\title{
The functions of institutions: etiology and teleology
}

\author{
Frank Hindriks ${ }^{1}\left[\right.$ [D $\cdot$ Francesco Guala ${ }^{2}$
}

Received: 22 August 2018 / Accepted: 25 March 2019 / Published online: 29 March 2019

(c) The Author(s) 2019

\begin{abstract}
Institutions generate cooperative benefits that explain why they exist and persist. Therefore, their etiological function is to promote cooperation. The function of a particular institution, such as money or traffic regulations, is to solve one or more cooperation problems. We go on to argue that the teleological function of institutions is to secure values by means of norms. Values can also be used to redesign an institution and to promote social change. We argue, however, that an adequate theory of institutions should not be 'moralized' in that they should not be defined in terms of the values they are supposed to promote.
\end{abstract}

Keywords Cooperation · correlated equilibrium · Etiology · Function · Institution · Norm · Teleology

\section{Introduction}

Institutions feature norms that constrain and enable. Consider traffic regulations. They prescribe several kinds of behaviors, such as driving on a particular side of the road and giving way to traffic from the right. In this respect, they constrain. At the same time, however, they make it possible for people to reach their destinations in a relatively efficient and safe manner. In this respect, they enable. As another example, consider marriage. In its monogamous manifestation, it requires both spouses to limit their sexual relations to their partner (constraint). However, in principle it also provides for a secure environment for raising children such that parents have the time and resources to do so (enablement).

\footnotetext{
$凶$ Frank Hindriks

f.a.hindriks@rug.nl

Francesco Guala

francesco.guala@unimi.it

1 University of Groningen, Groningen, The Netherlands

2 University of Milan, Milan, Italy
} 
The claim that institutions constrain and enable can be used to shed light on the function of institutions. As is widely accepted, institutions enable societies to cooperate in ways that benefit all or at least many of their members. We argue that the function of an institution is to promote cooperation and thereby to generate cooperative benefits. This claim has been made before, by Schotter (1981) and Tuomela (2007, 2013) among others. In this paper we give further substance to it by explicating it in terms of an etiological account of functions. More specifically, we argue that generating cooperative benefits is the causal or etiological function of institutions because it serves to explain why institutions exist and persist (Wright 1973; Millikan 1993). The etiological function of a specific institution such as money or traffic regulations depends on the particular cooperation problems it solves. Norms contribute to the performance of a function by changing the incentives people have.

Etiological functions are sometimes contrasted with teleological functions. The former are causal, the latter evaluative. As we discuss below, Searle (1995, 2010) presents a teleological account of institutional or status functions that people impose on entities against the background of their values. Status functions feature norms, or in Searle's terms 'deontic powers.' We criticize Searle's teleological account arguing that the deontic powers of which status functions consist can be explained in etiological terms. At the same time, we recognize that the evaluation of the performance of institutions is of crucial importance, in particular for political purposes. In light of this, we proceed to complement the etiological account we present with a teleological account.

John Rawls (1971) famously characterized society as a cooperative system. He also defended the normative claim that society should be a fair system of cooperation between free and equal persons. If Rawls is right, the major institutions of a society-its basic structure-should be evaluated in terms of the extent to which they succeed in securing fairness. Evaluating institutions in this manner is the first step to redesigning them and improving the way in which they function causally. The functions that are projected onto entities during this process are evaluative or teleological functions.

In this paper, we introduce an integrated framework of the etiological and teleological functions of institutions. This framework contributes to understanding what institutions do, how they do it, and what they should do. First, it serves to explain how institutional norms contribute to their etiological function. Second, it reveals how the notion of a teleological function can enrich institutional evaluations in a way that is informed by how they operate causally.

A third feature of our framework is that it is not moralized: it does not assume that particular norms, values, or rights are correct, and can as such be combined with different moral codes. In this respect, it differs from Miller's $(2001,2010)$ theory of institutions. Miller maintains that institutions do and should provide certain collective goods. His theory presupposes a particular conception of the moral rights that individuals have, which makes it inflexible in a way we regard as unattractive. We present our framework in Sects. 3 and 4 and compare it to its rivals in Sects. 3.3 (Searle) and 5 (Miller). But first we briefly introduce an account of institutions-a theory of what institutions are - that will provide the backdrop for our framework. 


\section{Institutions as rules in equilibrium}

Developing an account of the functions of institutions requires a theory of institutions. Institutions are often explicated in terms of rules (Hodgson 2006; Knight 1992; Mantzavinos 2001; Parsons 1935; Weber 1910). Famously, the Nobel Prize winning economist Douglas North claimed that they are 'the rules of the game of society or, more formally, the humanly devised constraints' that 'establish a stable structure to human interaction' (North 1990, p. 6). Such rules indicate what behavior is appropriate in given circumstances. The institution of private property, for example, regulates the use of resources by indicating who has access to them. And the institution of marriage regulates the behavior of two or more individuals who pool their resources to raise children, manage property, and help each other in various ways.

According to a second widespread view, institutions are solutions to problems that arise when people interact. More specifically, they are solutions to repeated coordination and cooperation problems as analyzed within game theory (Aoki 2001; Bicchieri 2006; Binmore 2010; Calvert 1998; Hedoin 2017; Lewis 1969; Schotter 1981; Sugden 1986). Such solutions are equilibria, which means that they generate regularities of behavior in the course of repeated games. The point of departure of game-theoretic accounts of institutions is a game form that specifies the preferences that agents have and the actions or strategies that are open to them. Within a particular game, agents maximize their utility by taking into account how others are likely to behave. Each player selects the action or strategy that is the best response to the actions of other players, which means that no one has an incentive to deviate from her strategy. In the situations at issue no individual can determine the outcome all by herself. Instead, it depends not only on her actions, but also on those of others. In this sense, the outcome is collective.

These two schools of thought about institutions need not be seen as rivals but can be regarded as complementary. The claim that an institution consists of rules indicates that they guide behavior, but as such it reveals nothing about the incentives people have. Equilibria accounts reveal that effective institutions are backed up by a system of incentives and expectations that motivate people to follow the rules. In light of this, a number of hybrid theories have been proposed (Aoki 2007; Greif and Kingston 2011). Elsewhere we have proposed what we call 'the Rules-in-Equilibrium account of institutions' (RiE), which we briefly summarize here (Hindriks and Guala 2015; Guala and Hindriks 2015; Guala 2016). Although other hybrid theories can be used to support claims similar to the ones defended below, we believe that $R i E$ provides for a particularly perspicuous and powerful way of doing so.

A distinctive feature of $R i E$ is that it invokes correlation devices in order to explain institutional behavior. ${ }^{1}$ Many institutions are solutions to coordination problems, which have multiple equilibria. A correlation device is a mechanism indicating which action each player should select in a given coordination game. Consider a simple problem of traffic regulation. Suppose that two drivers, Ann and Bob, meet very often at a crossroad. In the absence of a traffic light, there are three obvious strategies that they

\footnotetext{
${ }^{1}$ The notion of correlated equilibrium is due to Aumann $(1974,1987)$. See also Vanderschraaf (1995, 2014) and Gintis (2007).
} 
could follow: Ann stops and Bob goes; Ann goes and Bob stops; they both toss a coin and stop or go with fifty percent probability. The first two solutions are intuitively unfair, if regularly implemented, because they favor systematically one of the drivers. The third solution, however, is inefficient: half of the time, Ann and Bob will have an accident.

These are the 'natural' equilibria (so to speak) of this game and none of them looks very attractive. But fortunately, other 'artificial' solutions are available. Suppose that a traffic light is introduced, which serves to correlate and coordinate Ann and Bob's behavior. If they play the conditional strategy 'Stop if red, go if green', they will obtain an equilibrium that is efficient. This equilibrium was not available in the original game. A new equilibrium, which benefits both Ann and Bob, becomes available thanks to the introduction of the traffic light. Such equilibria are not only relative to a particular kind of situation, but also conditional on a correlation device. ${ }^{2}$

Using the notion of correlation device, the RiE account is able to unify gametheoretic accounts of institutions (such as Schotter's 1981, or Lewis' 1969) with those accounts that emphasize the enabling power of institutions (such as Searle's 1995, 2010). The grammatical form of players' strategies is crucial in this respect: in models of institutions that do not feature correlation devices, strategies have the form 'do $A$ '. The behavioral regularity that counts as a convention, for example, is 'everyone does $A$ '. In order for such a regularity to be a convention, people have to expect that everyone does $A$. Furthermore, given that people conform to the regularity and expect everyone to do so, they prefer to do so themselves as well (Lewis 1969, Schotter 1981, Bicchieri 2006). However, when a game features a correlating device that gives rise to a new equilibrium, then what people do is conditional on the presence of such a device. Using ' $D$ ' for correlating device, the structure is: 'If $D$, do $A$ '. A rule that has this form opens a new possible equilibrium. The device marks it as such. In other words, it signals the availability of the new strategies to the agents. Consider the traffic example used earlier. A traffic light introduces two new strategies: If red, stop; if green, go. Regulative rules - the rules that constitute an institution, according to the $R i E$ theory-have this same structure: 'If $X$, do $Y$ '. ${ }^{3}$

Within the context of an institution, certain actions cease to be attractive options. When everybody drives on the left, it is irrational to drive on the right. In this sense, the rules of the game constrain behavior. Even though it is a platitude that institutions also enable, it is rarely made clear in what sense they do so. In light of our analysis of institutions, we propose that an institution enables people to adopt new strategies and to achieve goals they could not reach otherwise. Correlation devices make new strategies available. Furthermore, by constraining behavior institutions tend to promote cooperation. As a consequence, an institution generates beneficial collective outcomes

\footnotetext{
2 Correlation devices can also be naturally occurring entities. Elsewhere we discuss an example of two groups who determine where to graze their cattle using a river bed as signal (Guala and Hindriks 2015). The notion of correlation device is particularly important for the purposes of this paper, because it serves to make sense of the role that institutional entities such as traffic lights, dollars, and wedding rings play in the institutions of traffic, U.S. American money, and marriage. See Sect. 5.

3 On the notion of 'regulative rule', see Searle's (1969) seminal work. In previous publications (Hindriks 2009; Hindriks and Guala 2015; Guala and Hindriks 2015) we have shown that Searle's theory of institutions - and in particular his notion of constitutive rule-can be derived from the RiE framework.
} 
that could not be brought about in its absence, or in the absence of other institutions. Those collective outcomes tend to benefit individual participants. We use this insight as the point of departure for an analysis of the etiological function of institutions.

\section{The etiological function of institutions}

\subsection{Cooperative benefits}

This theory of the enabling role of institutions suggests naturally that the function of institutions is to bring about collectively beneficial outcomes. Schotter (1981) and Tuomela $(2007,2013)$ have proposed accounts of the function of institutions along these lines. Schotter regards institutions as equilibria and thereby as regularities in behavior. He defines an institution as 'a regularity in social behavior that is agreed to by all members of society, specifies behavior in recurrent situations, and is either self-policed or policed by some external authority' (Schotter 1981, p. 11). According to Schotter, institutions can be classified in terms of the problems they solve, as well as in terms of the kind of coordination mechanism they rely on. Schotter argues that their function is 'to make our lives more efficient', or to solve collective problems 'with a minimum of social resources' (Schotter 1981, p. 22).

Tuomela argues that the function of institutions is their tendency 'to solve (or dissolve) coordination problems and collective action dilemmas'; he adds that they 'give cooperative, collectively beneficial solutions to these problems' (2013, p. 229; see also 2007). There are, however, a number of notable differences between their views, two of which deserve to be singled out here. First, Tuomela (2013) characterizes institutions as norm-governed social practices. Thus, Tuomela regards institutions as explicitly normative phenomena, which Schotter does not. We return to this in Sect. 4. Second, whereas Schotter explains institutions in terms of individual preferences and expectations, Tuomela invokes collective beliefs and intentions. Instead of actions that individuals perform independently, such collective attitudes give rise to actions that agents perform together, such as dancing the tango or interviewing job candidates.

The distinction between individual and collective attitudes can be used to distinguish between different senses in which participants can be said to cooperate. The individual actions modeled by game theory concern strategic interaction, as agents take the preferences and expectations of others into account when deciding what to do. Individual actions are interdependent in that together they generate collective outcomes - in the best cases they bring about collective outcomes that benefit each of the players. Thus, the players can be said to cooperate in an attenuated sense. But people who act together can also be said to cooperate in a richer, more intuitive sense of the term. They conceive of themselves as members of a group that have one and the same goal.

In light of this, the difference between these two views is that Schotter relies on a weaker conception of cooperation than Tuomela. ${ }^{4}$ What they share is the claim that

\footnotetext{
4 Tuomela (2013) argues that this difference has an explanatory payoff. Joint intentions give rise to more cooperative benefits than individual intentions, and thereby that institutions supported by joint intentions function better than those supported by individual intentions.
} 
the function of institutions is to provide cooperative benefits. In the rest of the paper we will speak of 'cooperation' generically, without taking a specific stance on this matter. The goal is to outline a theory that is compatible both with Schotter's and with Tuomela's approach. ${ }^{5}$

\subsection{Institutions and functions}

Against the background of game-theoretic accounts of institutions, it is rather intuitive to claim that it is the function of institutions to bring about cooperative benefits. Even so, neither Schotter nor Tuomela explicates in which sense this is their function. Because of this, it remains to be seen whether this claim survives closer scrutiny. The literature on functions in the philosophy of biology offers useful resources to tackle this issue. According to Wright's (1973) etiological conception, an entity has function $F$ exactly if the following two conditions are satisfied: First, the entity is there because it does $F$; second, $F$ is a consequence of the entity's being there. According to the first condition, the fact that the entity does $F$ accounts for its existence (the heart is there because it circulates blood). The second condition reveals that the fact that it does $F$ is not an accident (the heart plays a non-redundant role in explaining the circulation of blood). ${ }^{6}$ This etiological concept is closely related to that of an equilibrium, or so we argue.

The etiological function of an entity explains in particular why it continues to exist (or, in other words, why it persists). Blood circulation is of vital importance to organisms that have a heart. Some such organism would not be there if it were not for the fact that it has a heart. Furthermore, it remains in existence because it has a heart that circulates blood. This reveals that functions tend to be self-reinforcing. According to the Rules-in-Equilibrium account $(R i E)$, institutions are equilibria that offer cooperative benefits, and because of those benefits, those equilibria tend to be stable and self-reinforcing. This reveals that conceptualizing institutions as equilibria is useful for explaining their persistence.

Equilibrium accounts are usually less informative when it comes to explaining how an entity comes into existence. ${ }^{7}$ We do not know of a satisfactory and broadly

\footnotetext{
5 As a consequence, we will not be using the term 'cooperative' in its technical game-theoretic sense. The solution to a coordination problem for example may be cooperative in the broad sense employed here.

6 A number of more recent and more sophisticated analyses of functions share these features with Wright's proposal. Consider in particular Ruth Millikan's analysis:
}

For an item $\mathrm{A}$ to have a function $\mathrm{F}$ as a proper function it is necessary (and close to sufficient) that one of these two conditions should hold. (i) A originated as a "reproduction" (to give one example, as a copy, or a copy of a copy) of some prior item or items that, due in part to possession of the properties reproduced, have actually performed $\mathrm{F}$ in the past, and A exists because (causally historically because) of this or these prior performances. (ii) A originated as the product of some prior device that, given its circumstances, had performance of $\mathrm{F}$ as a proper function and that, under those circumstances, normally causes $\mathrm{F}$ to be performed by means of producing an item like A. (Millikan 1993, p. 23)

The claims we defend also hold on Millikan's proposal.

7 For a through discussion of this point, in the context of evolutionary and rational choice explanations, see Pettit (1996). 
applicable account of the emergence of institutions. Note, however, that the attribution of a function to the heart does not require a complete history of this organ. What is required instead is a convincing account of how the fact that the entity does $F$ explains its existence. It is rather plausible that the fact that institutions generate cooperative benefits fulfills this role. Arguably, these benefits play a crucial role in the selection process that only some institutions survive. ${ }^{8}$

Etiological functions are widely used for classificatory purposes. A particular type of institution is defined by the particular coordination or cooperation problems it solves. We illustrate this for the case of money. As compared to monetary economies, barter economies are notoriously inefficient. To the extent that an economy involves some division of labor, it faces the problem of the double coincidence of wants. Consider the following example: Ann produces meat, Bob vegetables, and Caroll fruit. If Ann wants vegetables but Bob is not interested in meat, Ann faces a problem. She cannot trade her meat for Bob's vegetables and has to work her way around this. She would not face this problem in a monetary economy. Thus, money confers considerable cooperative benefits on a society. One of its functions is to solve the problem of the double coincidence of wants. It does this by serving as a means of exchange.

\subsection{Deontic powers and functions}

To appreciate the distinctive character of this approach, let us compare it to a theory of institutional functions according to which they are not etiological. Searle $(1995 ; 2010)$ maintains that institutional or status functions are imposed (ultimately) on physical entities. Furthermore, he claims that they come with deontic powers, or rights and obligations. Using one of Searle's examples, the stones that remain from a city wall can function as a border. They mark the obligation not to cross this boundary. Similarly, the status function of a passport indicates that the relevant person has the right to travel to another country. This suggests that the function of an institution is that its deontic powers be performed.

These initial claims are in principle amenable to an etiological interpretation. However, Searle does not invoke the performance of deontic powers to explain the existence and persistence of institutions. Furthermore, he adamantly denies that the notion of a function in general and that of a status function in particular are causal. Crucially, Searle (1995: pp. 9-18) maintains that people assign functions to entities relative to particular values. In this sense, they are observer-relative. As they are not to be found in nature, functions cannot be explicated in terms of causal facts. For instance, when people claim that the function of the heart is to pump blood, they assign a teleology to the relevant causal processes that centers on the value of life. Because he regards the

\footnotetext{
8 Some philosophers are skeptical of such claims because many cooperation problems remain unsolved and many solutions are bad (see e.g. Brennan et al. 2013). However, it is easy to show that many explanations of bad solutions are consistent with our approach (Brennan et al. 2013, chapter 8). Moreover, there is currently no agreement on how the issue of unsolved problems should be addressed, a project that would require another paper. Here we only account for the tight link between attributions of functions and explanations of the continued existence of a type of entity, while noticing that its emergence is often a haphazard process.
} 
notion of a function as inherently evaluative, Searle rejects etiological accounts (ibid.: 15-17). It follows that his account is teleological. ${ }^{9}$

To be sure, the performance of deontic powers has causal consequences. In order for them to be performed, the status functions have to be collectively accepted. Once this is the case, people can, for instance, be prohibited from crossing the city boundary or legally travel abroad. However, on Searle's view, the claim that the functions of these institutions consist of fulfilling these deontic powers can be made only from the perspective of an observer. And it presupposes a set of purposes or values that are not part of the institutions as such. It follows that functions play no explanatory role in Searle's theory.

The existence and persistence of an institution is due to the fact that its deontic powers are collectively accepted. For Searle, however, there is no causal connection between the fact that those powers are fulfilled and the fact that an institution remains in existence. For example, the authoritarian government of an impoverished country remains in power as long as it is collectively accepted, irrespective of whether it serves a purpose. This disassociation between the causal mechanism that sustains institutions, on the one hand, and their functions, on the other, highlights the non-etiological nature of Searle's functions.

We discuss teleological accounts more fully in the next section. Here we just mention briefly why we believe that deontic powers should feature in an etiological account of the function of institutions. The main reason is that deontic powers contribute to the ways in which institutions actually function. As mentioned in Sect. 2, institutions can be explicated in terms of normative rules. Such rules feature deontic powers. ${ }^{10}$ And partly because of that, those rules promote cooperation. This, in turn, is conductive to the performance of institutional functions. The rules feature in the attitudes of the participants of an institution, perhaps as normative expectations (Bicchieri 2006). And they typically affect the preferences that agents have such that they will be inclined to cooperate or do so more robustly. In this way, they have a causal impact and contribute to the persistence of institutions.

We do not mean to imply that normative rules and deontic powers cannot play a role in an account of the teleological function of institutions (more on this below). Instead, we propose that deontic powers should feature in an account of the etiological function of institutions. In turn, such an account should be embedded in a framework that also explicates the teleological function of institutions. The next section is devoted to this task.

\footnotetext{
9 To be sure, Searle (1995) characterizes status functions not only as non-causal, but also as agentive. This means that they affect what people do. Even so, they do not causally explain the existence and persistence of certain entities. Note also that Searle is not concerned with entities, but with facts. Recently, he has explicitly denied the existence of institutional objects (Searle 2014). This reveals that his aim is different from ours, which is to explicate the causal or etiological function of institutional objects.

10 Elsewhere, we refer to such rules as 'status rules' (Hindriks 2009, 2013; Hindriks and Guala 2015; Guala and Hindriks 2015).
} 


\section{The teleological function of institutions}

\subsection{Benefits and values}

Institutions are norm-governed social practices (Tuomela 2013). The Rules-inEquilibrium account $(R i E)$ accommodates the normative or deontic dimension of institutions by invoking normative rules. Recall the rules discussed in Sect. 2. Their structure is: 'If $D$, do $A$.' These are descriptive rules. Rules that feature obligations are normative rules. Their structure is: 'If $D$, it is obligatory to do $A$ ' ${ }^{11}$

The next step is to capture the evaluative or axiological dimension of institutions. Norms serve to protect interests or realize values. Some norms moreover can promote interests or values. First-come-first-serve norms foster efficiency and fairness. Think, for example, of customers at a retail store who queue behind service checkout stations, or of property that is recognized by the right of first possession or occupation (Smith 2015). Other norms prescribe actions that support respectful interactions between people. This holds for instance, for many established ways of greeting others, or for ceremonies for highly ranked officials. Such norms do not promote a value in the sense of generating a valuable outcome. Instead, they support values or constitute valuable states of affairs. Because institutions are norm-governed social practices, they typically secure values in one or both of these two ways.

Recall the traffic example in which Ann and Bob regularly meet at a crossroad. In the absence of a traffic light, they can do one of three things: either Ann or Bob can always take precedence, or they can randomize. In Sect. 2, we have evaluated these options only in terms of their efficiency. They can, however, also be evaluated in terms of fairness. The first two solutions are unfair: unless one of them has a special claim, why should he or she always be privileged? The third solution is more acceptable from this point of view, because the payoffs are symmetric, but unfortunately is inefficient: half of the time, Ann and Bob will have an accident. A new equilibrium becomes available when a traffic light is introduced. This solution is efficient and fair, as both drivers stand to benefit equally.

The relation between institutional norms and values can be captured in terms of the notion of a teleological function. As discussed above, an etiological function explains the existence and persistence of an entity. In contrast, a teleological function concerns what it is good for, the purpose that it serves or its significance. Whereas the etiological function of an institution is to generate cooperative benefits, its teleological function is to secure some value. To be sure, cooperative benefits are in some sense valuable. But this is relative to the preferences of individual agents. And the significance of an institution often goes beyond preference-satisfaction. To be sure, agents who participate in an institution can be motivated by a value that cooperation secures or by cooperation as such. However, the value that it serves can also be incidental to the goals people pursue. Now, there is no guarantee that an institution-or, for that matter, a system of institutions-consistently serve some value. Some norms might be beneficial but

\footnotetext{
11 This is the structure of a prescription. The structure of prohibitions is 'If in $S$, one ought not to do $Y$ '; that of permissions is 'If in $S$, it is not the case that one ought not to do $Y$ '.
} 
have no further point. However, other norms do serve a value, and sometimes even in a robust manner. They can plausibly be said to have a teleological function.

Rather than being explanatory, teleological functions play an evaluative role. ${ }^{12}$ Institutions are often evaluated in terms of the contribution they make to equality and freedom. Famously, Rawls (1971) regards society as a cooperative venture. Furthermore, he argues that it should be a fair system of cooperation between free and equal persons. Finally, such a system of institutions can be secured by implementing his principles of justice. The idea is that, if the core institutions of a society fit Rawls' principles of justice, they robustly realize fairness. If this is indeed the case, the teleological function of what Rawls calls 'the basic structure' is justice. ${ }^{13}$

It should be recognized, of course, that some institutions are not particularly good at realizing values - perhaps some fail in it altogether. Sally Haslanger (2000) points out, for instance, that prevailing gender norms often advantage or privilege men and disadvantage or subordinate women. Thus, norms can also present an obstacle for securing values. One might even question whether gender norms promote cooperation. They can in fact be rather divisive. And if they do indeed subordinate or oppress women, as Haslanger (2004) argues, it might seem almost offensive to suggest that they do so. Note, however, that an institution can generate cooperative benefits even when those benefits are distributed unequally. When it does, generating those benefits is the etiological function of the institution. It might be that, in the case of gender, the structure that unfair norms provide enables couples to secure a higher income as well as more time and resources for raising children, as compared to a situation in which there are no gender norms at all. As Cudd (2006) has noticed, once gender roles have been established, participants in this institution-including females-have an interest in behaving accordingly, even if they resent the inequalities they give rise to.

The upshot is twofold. First, an account of institutions that exclusively focuses on cooperative benefits leaves out something important. Institutional norms do not only foster cooperation, they also secure values. To the extent that they have one, their teleological function is to support values or promote them. Secondly, institutions can fall short of some ideal. Perhaps they disappoint because they realize less value than expected. Or they do not target a value that is generally acknowledged as desirable. This has the striking implication that an institution that serves its etiological function well may lack significance in other respects. For this reason, social change and institutional design are of vital importance to society.

\footnotetext{
12 To be sure, it could be that the teleological function of an institution is reflected in the mental states of the participants. But, in contrast to Searle, we do not require this.

13 More generally, liberal political thinkers believe that justice is the core value for the evaluation of institutions (Dworkin, 1981a, b; Nozick 1974; Sen 2009; Walzer 1983). Although they all explicate justice in terms of equality and freedom, there are huge differences between these theories of justice. Nozick (1974), for instance, explicates justice in terms of property rights and rejects the notion of distributive justice. And Cohen (1997) argues that ideals of justice extend beyond institutions to people's personal ambitions and ideals.
} 


\subsection{The design stance}

The teleological function of an institution consists of the values that it realizes. However, as the gender example reveals, an institution can also be evaluated with respect to values that it does not support or promote, or not sufficiently. Such evaluations play an important role in generating social change. They are made relative to a teleological function that the institution could or should serve. In order to explain how this works, we adapt the notion of a design stance. In this context, the point of adopting the design stance is to gauge the performance of an institution with respect to some value. This in turn can serve the purpose of redesigning an institution in a way that is deemed desirable.

According to Dennett (1987), adopting the design stance towards an entity is a matter of ascribing a purpose to it and explaining its behavior in terms of that purpose. It presupposes that the entity has parts that have functions that serve that purpose. Clearly, the design stance can be adopted with respect to entities that have in fact been designed. In such cases, the intentional agents who designed it have attributed purposes and functions to the entity. However, the design stance can also be adopted in the absence of a designer. In order to highlight this, Vermaas et al. (2011) distinguish two design stances, the intentional design stance and the teleological design stance. In contrast to the former, the latter does not presuppose intentional design. Instead, the entity may have been "designed" by other processes or mechanisms, such as natural selection. Someone who adopts the teleological design stance towards an institution projects a teleological function on it for the purpose of evaluation.

Dennett argues that the design stance is applied successfully to an entity only when doing so serves to successfully predict its behavior. Our account of teleological functions departs from his, in this respect. Suppose that people attribute equality as the purpose or function that gender roles should realize, or as the value they should secure. When prevailing gender roles in fact subordinate females, this assumption will not serve to successfully predict institutional behavior. The design stance can still be useful, however, even if it currently has no predictive or explanatory value. The reason is that people can attribute purposes and functions to institutions (as well as to their parts) relative to certain goals or values that should be realized. Doing so will be useful for some agent, perhaps a group agent such as the government, that wants to adopt the role of designer, and set out to reform the relevant institutions. The goal of redesigning them is to transform them in such a way that they come to (better) fulfill their teleological function.

Evaluating a particular society in terms of justice requires adopting the design stance. A poor evaluation provides reason for redesigning its institutions. Rawls goes as far as to claim that 'laws and institutions no matter how efficient and well-arranged must be reformed or abolished if they are unjust' (1971). In order to suitably redesign an institution, it is important to determine how the parts can be configured such that the institution comes to better realize justice. This is where teleology and etiology, or values and explanations meet. It should be emphasized, however, that, even if justice is the teleological function of the core institutions of society, someone who adopts the design stance can ignore the connection with justice and evaluate institutions with 
respect to some other value. In this respect, our framework is neutral. Theological considerations, for example, may influence the design of institutions in those societies that prioritize religious values.

The upshot is that the etiological function of institutions is to generate cooperate benefits, whereas their teleological function is to secure values. As it accommodates these two kinds of functions, the account we have offered is a hybrid theory of the functions of institutions. Its main advantage is that it is comprehensive. It also explains why functionalism is often contested in the philosophy of social science: no single notion of function can do all the things that functionalist accounts typically require. A hybrid theory based on two concepts, instead, may be up to the task. Furthermore, our discussion of liberal political theory illustrates how the etiological function can inform the teleological functions that are ascribed to institutions. Finally, it reveals how function talk can enrich their normative evaluation.

\section{Collective ends and collective goods}

As far as we know, there is only one other theory of institutions that can make a claim to providing a comprehensive account of their functions. This is Milller's (2001, 2010) collective end theory. According to the Rules-in-Equilibrium account $(R i E)$, institutions can be the unintended consequences of individual actions. Although Miller recognizes that they often involve unintended consequences, he argues that institutions serve to realize what he calls 'collective ends.' A collective end is an individual end held in common by a number of individuals that is (to be) realized by all or most of them. Joint actions are interdependent individual actions directed at collective ends. Each individual who performs a joint action adopts a particular collective end, intentionally performs an action that contributes to this end, believes that every other individual did, does, or will do so, and mutually believes that all of this is the case. Institutions are joint activities governed by social norms in accordance with collective ends. Finally, the function of an institution is to realize the collective end that defines it (Miller 2010, p. 25).

According to Searle, the function of an institution is to fulfill its deontic powers. Those deontic powers feature in the mental states of the participants-they are collectively accepted. In a similar vein, Miller maintains that the function of an institution is to realize a collective end. And this collective end figures in the mental states of the participants in that it forms their goal. The main difference between them is that Miller relies on a causal conception of functions. This is apparent from the fact that he invokes the function of an institution in order to explain its 'reproductive capacity' (Miller 2010, p. 95). Institutions come into existence by several individuals performing joint actions aimed at a collective end (in accordance to social norms). Collective ends however do not only explain how institutions come into existence, but also how they persist. Institutions tend to reproduce themselves in large part because participants identify with and have long-term commitments to institutional ends. In light of this, we take Miller's account to concern the etiological function of institutions. ${ }^{14}$

\footnotetext{
14 Miller (2001, 2010) characterizes his theory of institutions as teleological, because the notion of a collective end is a teleological notion. Even so, the fact that people adopt collective ends plays a causal role
} 
Miller complements this descriptive account with a normative account of institutions. According to this account, the collective ends of institutions are collective goods. Such goods are jointly supplied by organizations to the entire community. Furthermore, because they are morally desirable, the members of the community are entitled to these goods. More specifically, they have a joint moral right (Miller 2010, p. 4 and p. 64). Finally, institutions should secure such rights. Although Miller does not use the term 'function' in this connection, securing joint moral rights can plausibly be regarded as the teleological function of institutions. They perform this function by providing collective goods. On this interpretation, Miller offers a hybrid and complete theory of the functions of institutions, just as we claim to do.

Both parts of the theory, however, face severe problems. Insofar as the descriptive account is concerned, we question whether things line up as neatly as Miller has it. On his view, the collective end that is definitive of an institution is the collective end that it in fact realizes, if it does indeed suitably perform its function, because its participants subscribe to it. However, granting that institutions have constitutive ends, it is an empirical matter whether they are supported. Furthermore, the collective end that an institution actually realizes might be different from the one that is definitive of it.

By way of example, consider marriage. Miller argues that, even though some couples do not marry explicitly for this purpose, all of them implicitly have a 'collective end to reproduce the institution of the nuclear family' (2010, p. 96). But why would we believe that a couple that believes that it gets married merely because of tax benefits implicitly has this collective end? Consider also people who get married in their eighties, or people who got sterilized prior to getting married. Miller's claim is difficult if not impossible to square with such cases. Furthermore, even if reproducing the nuclear family is the constitutive end of marriage, it could in principle be that this actually plays only a minor role in sustaining the institution. Perhaps marriage primarily serves to privilege men over women. Thus, there can be a double dissociation between the constitutive end of an institution, the ends of its participants and the end it actually serves.

As another example, Miller proposes that the collective end of a university is 'the acquisition, transmission, and dissemination of knowledge' (Miller 2010, p. 279). Now, even if this is true, it does not entail that those who work for a university have this as their end. Faculty might care only about publications or prestige. And staff might regard what they do as just another job and not care about knowledge at all. Even the president of a university might be more interested in her personal pet projects than in knowledge as such. If this is the case, the ends that the participants have diverge from the collective end that is definitive of the institution. And we see no reason to implicitly attribute the collective end mentioned to each and every member of such a university. To be sure, we do not want to deny that participants might have aims that are closely related to the teleological function of an institution. However, whether they do is an empirical issue. Because of this, we believe that it is problematic to insist that the function of an institution be reflected in the mental states of its participants.

Footnote 14 continued

in his theory. Because of this, Miller's characterization of his theory of institutions is consistent with our claim that his account of functions is etiological. 
Furthermore, this collective end might not be the only one that is in fact realized. It is widely recognized, for example, that education fulfils an important signaling function: it offers employers the opportunity to identify highly motivated and skilled workers, separating them from those who do not have the capacities or the interest to engage in cognitively demanding, time-consuming tasks. Now, it might be that a university performs this signaling function because it contributes substantially to the collective good of knowledge acquisition and dissemination. However, it could also be that, perhaps because it gives a lot of weight to legacy considerations, the university actually serves to uphold existing socio-economic networks and maintain the status quo while doing a poor job at knowledge dissemination. Again, there is a double disassociation between (ordinary) individual ends, collective ends and collective goods. Thus, Miller's descriptive account of the functions of institutions is hard to sustain. ${ }^{15}$

In response, Miller might claim that institutions that do not serve their constitutive collective ends are simply not of the type to which they appear to belong. But how credible is this? Consider two couples who have gone through the exact same procedure. However, only the members of one of these couples have the collective end 'to reproduce the institution of the nuclear family.' It defies credulity to say that this second couple is married, whereas the first is not.

The issue is more complex when it comes to organizations. The insight that we take away from Miller's account is that our classificatory practices have, in some cases, come to regard etiological functions as constitutive of a particular kind of organization. However, we submit that there are cases where our classifications present goals as constitutive that are not in fact the etiological functions of the institution. Consider the church as an example. According to the dictionary, this type of organization serves to promote religious worship. However, sociologists might discover that the real etiological function is to promote social cohesion, as that is what explains its persistence. Because our account is more flexible, it is compatible with many different ways of labeling institutions, and seems therefore preferable to Miller's descriptive account. In the case of organizations, etiological functions and the functions that are definitive of institutions often align. However, as the church example shows, there can still be cases in which they come apart.

The problem with Miller's normative account is not that it is wrong, but that it is rather limited. Recall that, on our reconstruction of Miller's theory, the teleological function of institutions is to secure joint moral rights by providing collective goods. The attraction of our theory, we propose, is that it is both more flexible and more general. Miller's approach is tied to a particular way of evaluating institutions, to wit in terms of joint moral rights that are based on a particular moral code. Furthermore, it is moralized in that this is deemed to be the right way of evaluating institutions. Miller is committed to the claim that an institution that underperforms harbors agents that violate moral rights. In contrast, our approach is not tied to a particular moral code. Proponents of perspectives as diverse as anarchism and totalitarianism could use it for

\footnotetext{
15 Miller's account of the private sector is more permissive. He argues that 'each owner and manager ... has-jointly with the others-an implicit and (much of the time) latent collective end to reproduce the market system.' (2010, p. 96) But he allows for the possibility that this does not hold for other participants of the institution, such as ordinary employees. Even so, we fail to see how Miller can rule out exceptions pertaining to owners and managers even though the claim he makes is an empirical one.
} 
their purposes. Furthermore, it is not moralized. A poor evaluation on some dimension need not entail that any of the participants does anything wrong. The framework leaves open whether there even is a right way of evaluating institutions. In these respects, our approach is more flexible.

It is also more general. Just as Miller's account, it accommodates moral rights (irrespective of whether they serve to protect morally significant interests or sustain moral values such as autonomy, as Miller assumes). But it is not confined to them. It can be used to evaluate institutions in terms of how well they perform with respect to values as diverse as freedom, friendship, and frugality. Because of this, it is particularly apt for liberal societies that acknowledge a multiplicity of values. Our framework also allows for evaluating institutional phenomena with respect to non-moral values. Think, for instance, of school holidays and whether the way they are scheduled across the country is optimal when it comes to avoiding traffic congestion and overcrowding of recreational facilities. This is mainly a matter of efficiency, rather than morality, and any plausible theory of the functions of institutions must be able to account for cases like this.

\section{Conclusion}

Institutions are often analyzed either in terms of rules, or in terms of equilibria. We have presented a hybrid theory on which they are both. Against the background of this Rules-in-Equilibrium account $(R i E)$, we have argued that the etiological function of institutions is to generate cooperative benefits. Their cooperative benefits explain the (continued) existence of institutions. Some philosophers, like Searle for example, deny the existence of etiological functions. In contrast, we have argued that the functions of particular institutions are defined by the cooperation problems that they solve. For instance, the function of money is to serve as a medium of exchange. It generates cooperative benefits by facilitating market transactions.

Institutions however can also be seen as norm-governed social practices, and the norms of institutions serve in principle to support or promote values. The teleological function of an institution is to secure some value. According to a widespread view, the major institutions should be evaluated in terms of their contribution to a just society. This requires adopting a design perspective, which is a matter of ascribing a purpose to them and appreciating their behavior in terms of that purpose. Institutions are then evaluated against the background of a purpose or teleological function that is projected onto it.

The values that agents project onto institutions, however, do not define their identity. Any theory that strictly identifies an institution with some moral value or right, will necessarily miss the variety of teleological functions that any given institution can and often is attributed for the purposes of evaluation and reform. To illustrate this point, we have discussed and criticized Miller's theory, which focuses too narrowly on collective goods and joint moral rights. A hybrid account like ours, we believe, is better suited to understand the way in which (and the reason why) teleological functions are projected on institutions to promote citizens' interests in social change. 
Open Access This article is distributed under the terms of the Creative Commons Attribution 4.0 International License (http://creativecommons.org/licenses/by/4.0/), which permits unrestricted use, distribution, and reproduction in any medium, provided you give appropriate credit to the original author(s) and the source, provide a link to the Creative Commons license, and indicate if changes were made.

\section{References}

Aoki, M. (2001). Toward a comparative institutional analysis. Cambridge, MA: MIT Press.

Aoki, M. (2007). Endogenizing institutions and institutional changes. Journal of Institutional Economics, $3(1), 1-32$.

Aumann, R. J. (1974). Subjectivity and correlation in randomized strategies. Journal of Mathematical Economics, 1(1), 67-96.

Aumann, R. J. (1987). Correlated equilibrium as an expression of bayesian rationality. Econometrica: Journal of the Econometric Society, 55(1), 1.

Bicchieri, C. (2006). The grammar of society. Cambridge: Cambridge University Press.

Binmore, K. (2010). Game theory and institutions. Journal of Comparative Economics, 38, 245-252.

Brennan, G., Eriksson, L., Goodin, R. E., \& Southwood, N. (2013). Explaining Norms. Oxford University Press.

Calvert, R. L. (1998). Rational actors, equilibrium, and social institutions. In J. Knight \& I. Sened (Eds.), Explaining social institutions. Ann Arbor, MI: University of Michigan Press.

Cohen, G. A. (1997). Where the Action Is: On the Site of Distributive Justice. Philosophy Public Affairs, 26(1), 3-30.

Cudd, A. E. (2006). Analyzing oppression. New York, NY: Oxford University Press.

Dennett, D. C. (1987). The intentional stance. Cambridge, MA: MIT Press.

Dworkin, R. (1981a). What is equality? Part 1: Equality of welfare. Philosophy \& Public Affairs, 10, 185-246.

Dworkin, R. (1981b). What is equality? Part 2: Equality of resources. Philosophy \& Public Affairs, 10, 283-345.

Gintis, H. (2007). The bounds of reason. Princeton, NJ: Princeton University Press.

Greif, A., \& Kingston, C. (2011). Institutions: Rules or equilibria? In Political economy of institutions, democracy and voting (pp. 13-43). Berlin: Springer.

Guala, F. (2016). Understanding institutions. Princeton, NJ: Princeton University Press.

Guala, F., \& Hindriks, F. (2015). A unified social ontology. The Philosophical Quarterly, 65(259), 177-201.

Haslanger, S. (2000). Gender and race: (What) are they? (What) do we want them to be? Noûs, 34(1), 31-55.

Haslanger, S. (2004). Oppressions Racial and Other, 1-16.

Hedoin, C. (2017). Institutions, rule-following and game theory. Economics and Philosophy, 33, 43-72.

Hindriks, F. (2009). Constitutive rules, language, and ontology. Erkenntnis, 71(2), 253-275.

Hindriks, F. (2013). The location problem in social ontology. Synthese, 190(3), 413-437.

Hindriks, F., \& Guala, F. (2015). Institutions, rules, and equilibria: A unified theory. Journal of Institutional Economics, 11(03), 459-480.

Hodgson, G. M. (2006). What are institutions? Journal of Economic Issues, 40(1), 1-25.

Knight, J. (1992). Institutions and social conflict. Cambridge: Cambridge University Press.

Lewis, D. K. (1969). Convention: A philosophical study. Cambridge, MA: Harvard University Press.

Mantzavinos, C. (2001). Individuals, institutions, and markets. Cambridge: Cambridge University Press.

Miller, S. (2001). Social action: A teleological account (pp. 1-322). Cambridge: Cambridge University Press.

Miller, S. (2010). The moral foundations of social institutions. Cambridge: Cambridge University Press.

Millikan, R. (1993). White Queen psychology and other essays for Alice. Cambridge, MA: MIT Press.

North, D. (1990). Institutions, institutional change and economic performance. Cambridge: Cambridge University Press.

Nozick, R. (1974). Anarchy, state, and Utopia. New York: Basis Books.

Parsons, T. (1935). The place of ultimate values in sociological theory. International Journal of Ethics, 45, 282-316.

Pettit, P. (1996). Functional explanation and virtual selection. The British Journal for the Philosophy of Science, 47(2), 291-302. 
Rawls, J. (1971). A theory of justice. Cambridge, MA: Harvard University Press.

Schotter, A. (1981). The economic theory of social institutions. Oxford: Oxford University Press.

Searle, J. R. (1969). Speech acts. Cambridge: Cambridge University Press.

Searle, J. R. (1995). The construction of social reality. New York: The Free Press.

Searle, J. R. (2010). Making the social world: The structure of human civilization. New York: Oxford University Press.

Searle, J. R. (2014). Are there social objects. In M. Gallotti \& J. Michael (Eds.), Perspectives on social ontology and social cognition (pp. 17-26). Dordrecht: Springer.

Sen, A. (2009). The idea of justice. Cambridge, MA: Harvard University Press.

Smith, V. L. (2015). Conduct, rules and the origins of institutions. Journal of Institutional Economics, 11(3), 481-483.

Sugden, R. (1986). The economics of rights, co-operation and welfare. Oxford: Blackwell.

Tuomela, R. (2007). The philosophy of sociality: The shared point of view. Oxford: Oxford University Press.

Tuomela, R. (2013). Social ontology. Oxford: Oxford University Press.

Vanderschraaf, P. (1995). Convention as correlated equilibrium. Erkenntnis, 42(1), 65-87.

Vanderschraaf, P. (2014). Learning and coordination. Abingdon on Thames: Routledge.

Vermaas, P. E., Carrara, M., Borgo, S., \& Garbacz, P. (2011). The design stance and its artefacts. Synthese, 190(6), 1131-1152.

Walzer, M. (1983). Spheres of justice. New York: Basic Books.

Weber, M. (1910). Diskussionsrede zu dem Vortrag von A. Ploetz über Die Begriffe Rasse und Gesellschaft. In Gesammelte Aufsätze zur Soziologie und Sozialpolitik (pp. 456-462). Tübingen.

Wright, L. (1973). Functions. The Philosophical Review, 82(2), 139-168.

Publisher's Note Springer Nature remains neutral with regard to jurisdictional claims in published maps and institutional affiliations 